\title{
Hanno Wijsman, Manuscrits illustrés dans les Pays-Bas bourguignons. Quelques remarques quantitatives
}

\section{Gianni Mombello}

\section{Q OpenEdition}

10 Journals

\section{Édition électronique}

URL : http://journals.openedition.org/studifrancesi/34342

DOI : 10.4000/studifrancesi.34342

ISSN : 2421-5856

Éditeur

Rosenberg \& Sellier

\section{Édition imprimée}

Date de publication : 1 novembre 2005

Pagination : 390-391

ISSN : 0039-2944

\section{Référence électronique}

Gianni Mombello, «Hanno Wijsman, Manuscrits illustrés dans les Pays-Bas bourguignons. Quelques remarques quantitatives », Studi Francesi [En ligne], 146 (XLIX | II) | 2005, mis en ligne le 30 novembre 2015, consulté le 18 avril 2021. URL : http://journals.openedition.org/studifrancesi/34342 ; DOI : https://doi.org/10.4000/studifrancesi.34342

Ce document a été généré automatiquement le 18 avril 2021.

\section{(c)}

Studi Francesi è distribuita con Licenza Creative Commons Attribuzione - Non commerciale - Non opere derivate 4.0 Internazionale. 


\title{
Hanno Wijsman, Manuscrits illustrés dans les Pays-Bas bourguignons. Quelques remarques quantitatives
}

\author{
Gianni Mombello
}

\section{RÉFÉRENCE}

HANNO WIJSMAN, Manuscrits illustrés dans les Pays-Bas bourguignons. Quelques remarques quantitatives, «Gazette du livre médiéval», 43, automne 2003, pp. 23-33.

1 Résumé partiel (un autre article est annoncé) d'une thèse de doctorat soutenue à l'Université de Leyde (juin 2003) dont la traduction en anglais est en préparation.

2 Cette recherche prend en considération seulement les Pays-Bas burgondohabsbourgeois (donc, Picardie exclue) pour une période qui va de 1400 à 1550, laps de temps bien choisi, puisqu'il couvre les décennies qui précèdent et qui suivent la diffusion de l'imprimerie. Le corpus examiné comprend 3400 volumes ou fragments de volumes.

3 Le but que le chercheur se proposait était celui de calculer le taux de survie des manuscrits ayant appartenu à des familles de la noblesse. Très élevé pour la Bibliothèque de Bourgogne (32\% environ, dans l'inventaire de 1420, sur 255 mss., il passe à $55 \%$ dans à l'inventaire de 1487 , sur 550 mss.), il peut tendre à zéro pour d'autres familles dont les fonds n'ont pas abouti à une bibliothèque institutionnelle.

Même si ces chiffres - et d'autres qu'on ne peut mentionner dans une notice - nous laissent perplexes à cause de leurs fourchettes, d'autres, par exemple ceux qui concernent la survie plus précaire des livres d'heures, sont fort intéressants. En effet, du moins en principe, plus le livre est précieux, plus il aura de chances d'être conservé même par des particuliers, mais cela ne semble guère compatible avec le taux de survie des livres d'heures (entre 7 et 15\%). 
$5 \quad$ Les résultats auxquels $\mathrm{H}$. Wijsman parvient ne sauraient être étendus à la totalité de la production manuscrite du Moyen Age finissant à la première moitie du XVI ${ }^{e}$ siècle. 